\title{
OS COMPÊNDIOS ESCOLARES DE GEOGRAFIA NO ESTADO NOVO: MITOS E REALIDADES
}

\author{
SÉrgio Claudino ${ }^{1}$
}

\begin{abstract}
Resumo - No Estado Novo, os autores de livros de Geografia para o ensino primário ignoram a supressão da disciplina, ditada nos anos 30. No ensino liceal, começa por existir uma legislação contraditória e uma produção de compêndios pouco disciplinada até que, em meados dos anos 50 , se inicia a aprovação de livros únicos de Geografia, de conceituados professores liceais. As autoridades insistem no carácter auxiliar dos compêndios, que deverão conter muitas ilustrações, elementos de consulta e um texto reduzido - o que dificilmente reconhecemos nos livros publicados. No final dos anos 60 , liberaliza-se a produção dos compêndios e adivinha-se um novo ciclo.
\end{abstract}

Palavras-chave: Geografia, Estado Novo, programas, compêndios, livros únicos, autores

Abstract - Geography teXtbooks DURING SALAZAR's Regime: MYTHS AND REALITIES. During the period of the New State, the authors of Geography manuals for the first years of schooling ignored the elimination of the subject from the curricula, dictated in the 1930's. In the high schools, there was a set of contradictory legislation and an uncontrolled production of Geography textbooks, but in the mid-1950's, an official textbook of Geography, conceived by important school teachers, was approved. The authorities regarded school textbooks as learning aids, which should therefore have a lot of illustrations, elements of research and short texts - which was hardly recognizable in the published textbooks. In the end of the 1960's, a period of free publishing, a new cycle begin. authors.

Key words: Geography, New State, curricula, textbooks, official textbooks,

Résumé - Les manuels scolaires de GÉographie à L'éPoque de Salazar: mythes et RÉALité. Pendant l'État Nouveau, les auteurs de livres de Géographie destinés à l'enseignement primaire ont ignoré la suppression de la discipline, décidée dans les années 30. En ce qui concerne l'enseignement secondaire, se manifesta d'abord une législation contradictoire et une production désordonnée, jusqu'à

1 Investigador do Centro de Estudos Geográficos e docente do Departamento de Geografia da Faculdade de Letras da Universidade de Lisboa. E-mail: sergioclaudino@netcabo.pt 
ce que soient approuvés des livres uniques de Géographie, élaborés par des professeurs réputés. Les autorités insistaient sur le rôle auxiliaires de ces manuels, qui auraient dû contenir de nombreuses illustrations et des documents, avec un texte réduit - ce qu'on n'observe guère dans les livres publiés. À la fin des années 60 , la production des manuels fut libéralisée et un nouveau cycle de production s'ouvrit alors.

Mots-clés: Géographie, État Nouveau, programmes, manuels, livres uniques, auteurs.

\section{AÇORES, 1955/6: CARLOS ALBERTO ESTUDA GEOGRAFIA PELO LIVRO DE PATRÍCIO E LOUREIRO}

O sistema altamente centralizado levou à criação dos chamados «livros únicos», oficialmente aprovados pelo Ministério da Educação Nacional e impostos a toda uma população escolar como únicos textos autorizados. A política do «livro único» foi também adoptada nas escolas primárias.

Oliveira Marques, 1984, p. 4963

Em Ponta Delgada, Carlos Alberto Medeiros tem o seu primeiro contacto com o ensino de Geografia na escola primária, a que se sucede, nos dois primeiros anos do Liceu de Antero de Quental, a aprendizagem de Ciências Geográfico-Naturais. Em 1955/6, no 3. ${ }^{\circ}$ ano, inicia a frequência da disciplina de Geografia e recorda ter estudado pelo compêndio de Amílcar Patrício e Júlio Leal de Loureiro - autores que o acompanharão até ao $5 .^{\circ}$ ano. Já nos $6 .^{\circ} \mathrm{e}$ 7. ${ }^{\circ}$ anos, terá o livro único de Evaristo Vieira e Alves de Moura.

No mesmo ano, Carlos Alberto estava longe de supor que Amílcar Patrício se encontrava nos Açores e que, para este autor, era uma data igualmente simbólica. Acabara de se efectivar como professor de Geografia do ensino secundário no Liceu Nacional da Horta, atingindo o topo da sua carreira profissional. Na véspera do Natal de 1955, o correio desembarcado na Horta traz-lhe uma grande notícia: as autoridades educativas do Estado Novo seleccionaram o compêndio de que é co-autor como livro único do $2 .^{\circ}$ ciclo liceal, que assim se torna de adopção obrigatória em todo o país. Esta é, também, a primeira aprovação de um livro único de Geografia.

Contudo, estamos longe de poder associar, simplisticamente, o Estado Novo ao estudo de Geografia em compêndios obrigatórios.

\section{ENSINO PRIMÁRIO: OS AUTORES IGNORAM A SUPRESSÃO DE GEOGRAFIA}

A primeira reforma da instrução primária elementar promovida pela Ditadura Nacional ocorre em 1927. Na 3. ${ }^{\text {a }}$ classe, os alunos abordam noções gerais de Geografia e alguns aspectos físicos de Portugal, sendo a classe seguinte 
dedicada à Corografia de Portugal e Colónias ${ }^{2}$. A reforma de 1929 acrescenta o estudo do Brasil $^{3}$ e, dias depois, abre concurso para aprovação governamental dos livros escolares que os professores poderão seleccionar ${ }^{4}$. As autoridades queixam-se da reduzida qualidade dos compêndios e autorizam, para Geografia, o livro do já consagrado Acácio Guimarães ${ }^{5}$. Alteram-se as regras de aprovação oficial e, em 4 de Novembro de 1931, são aprovadas, mas só condicionalmente, para as $3 .^{\mathrm{a}}$ e $4 .^{\mathrm{a}}$ classes, os livros de António Figueirinhas e de Vasconcelos e Sá, conhecido autor da $1 .^{a}$ República. À margem destas autorizações, inicia-se a publicação da semi-anónima Colecção Escolar Progredir, organizada por professores primários, multiplicando-se as suas edições dos compêndios de Corografia e de Geografia. AMorim Girão (1934) debruça-se sobre compêndios de Geografia para o ensino primário, critica-os pelo excesso de desenvolvimento dos conteúdos, mas elogia-lhes a ilustração - num balanço globalmente positivo.

Em 1936, o governo progride na sua política centralista: impóe livros únicos de leitura na instrução primária elementar e, no ensino não superior, nas disciplinas de História de Portugal, História Geral, Filosofia e Educação Moral e Cívica ${ }^{6}$. Apela-se a livros de abundante ilustração, descritivos, mas de texto limitado. No mesmo ano, o ensino primário é reduzido a Língua portuguesa, Aritmética e sistema métrico, Moral, Educação física e Canto coral ${ }^{7}$ - exclui-se, assim, a Geografia. Determina-se um livro único, com as matérias destas disciplinas, por cada classe. No ano seguinte, aprovam-se novos programas do ensino primário elementar apenas para as três primeiras classes, pela necessidade de elaborar o referido livro único ${ }^{8}$. Para 1937/38, mantém-se em vigor o programa da $4 .{ }^{\text {a }}$ classe, que compreende a Geografia. Em 1937, abre concurso para o livro único, mas as autoridades não conseguem reunir textos de qualidade. Ainda em 1961, tomam-se medidas para a concretização deste projecto, agora de acordo com os programas de 28 de Maio de 1960, integralmente repetidos em 16 de Julho de 1968. Estes instituem a disciplina de Ciências Geográfico-Naturais nas quatro classes, desenvolvendo-se nas primei-ras a observação do meio local e, na $4 .^{\text {a }}$ classe, o estudo do corpo humano, dos animais, das plantas, da terra e, com maior detalhe, de Portugal. Em $1961^{9}$, as autoridades decidem concentrar as suas atenções nos livros de leitura e de História de Portugal, que passam, agora, a livros únicos - o que efectivamente se concretiza. A escolha dos restantes livros é livre, de entre os aprovados

2 Decreto n. ${ }^{\circ}$ 14417, de 12 de Outubro de 1927.

3 Decreto n. ${ }^{\circ}$ 16730, de 13 de Abril de 1929.

4 Diário do Governo, II série, n. ${ }^{\circ}$ 86, de 15 de Abril, p. 1313-1314.

5 Diário do Governo, II Série, n. ${ }^{\circ} 260$, de 8 de Novembro, p. 3680.

6 Lei n. ${ }^{\circ}$ 1941, de 11 de Abril de 1936.

7 Decreto-lei n. ${ }^{\circ} 27279$, de 24 de Novembro.

8 Decreto n. ${ }^{\circ} 27603$, de 29 de Março.

9 Portaria n. ${ }^{\circ} 18518$, de 7 de Junho. 
oficialmente. Assim, o governo nunca consegue impor o livro único por classe, determinado em 1936, optando, muito depois, por uma solução mais moderada.

No ensino de Geografia, os autores escolares ignoram completamente a supressão da disciplina na $3 .^{a}$ classe, de 1936 . Este desrespeito poderá dever-se à compreensível discordância de que os alunos estudem Portugal na $4 .^{\mathrm{a}}$ classe, sem efectuarem a aprendizagem dos conteúdos introdutórios de Geografia. Apesar de só existir autorização para se ensinar o programa da $4 .^{\mathrm{a}}$ classe em 1937/38 (que compreende o ensino desta disciplina), ele é leccionado até ao começo dos anos 60. O ensino de Geografia e de outros saberes disciplinares subsiste, em ilegalidade formal, até ao começo dos anos 60. A reforma de 1960 demora alguns anos a chegar aos compêndios de Geografia - o ensino primário parece constituir um mundo com uma dinâmica própria forte, muito alheado das determinações oficiais.

No entanto, esta é uma desobediência consentida pelas autoridades. Através do Arquivo Histórico do Ministério da Educação, apercebemo-nos que a maioria dos livros não é sujeita a aprovação oficial e muitos dos textos candidatos a autorização estão já impressos. Ao longo de anos, o inspector Silvestre de Figueiredo é o único relator que assina os pareceres sobre os manuais; refere a inexistência de relações de causalidade, o excesso de pormenorização, a desvalorização da realidade próxima, a falta de imagens e as próprias incorrecções de redacção-mas acaba sempre por conceder a aprovação. Nunca contesta a inclusão nos compêndios dos conteúdos do extinto programa da $3{ }^{a}$ classe, a cujas recomendações se chega a referir. Apenas em 1952, a Junta Nacional de Educação decide a rejeição de compêndios por não estarem de acordo com o programa.

Muitos livros são de autoria anónima - o que traduz quer a desresponsabilização científica, quer a desvalorização social da autoria destes compêndios. A generalidade dos redactores dos livros escolares são pro-fessores primários, que frequentemente escrevem outros livros. Poucos serão conhecidos, como Américo Areal, que fundará uma editora ou o General João de Almeida, antigo director do Instituto de Ensino Normal de Braga, que se notabilizou como chefe militar em Angola. Entre os autores dos de Ciências Geográfico-Naturais para a $3 .^{\mathrm{a}}$ e $4 .^{\mathrm{a}}$ classes, de acordo com os programas de 1960, sobressai Pedro de Carvalho, outro professor primário, cujos livros muito ilustrados e patrióticos, se multiplicam em edições não identificadas e sem data, que a Porto Editora faz chegar a todo o país. Com menor expressão, surge António Branco, também pela Porto Editora. Ironicamente, desaparecem dezenas de autores, quando o poder político reconhece a liberdade de produção e de adopção de compêndios de Geografia. Emerge a força das principais editoras. 


\section{PRIMEIRA FASE DO ESTADO NOVO: LEGISLAÇÃO CONTRADITÓRIA E PRODUÇÃO INDISCIPLINADA}

No ensino liceal, a produção de compêndios divide-se em dois períodos, separados pela aprovação e implementação do Estatuto Liceal de 1947. No primeiro, o ensino de Geografia sofre uma acentuada desvalorização, sucede-se a aprovação de legislação por vezes contraditória e vive-se uma situação confusa na produção de compêndios. No segundo período, a Geografia recupera o seu protagonismo no ensino liceal e é implementado o livro único, que subsiste, formal ou informalmente, até à Revolução de 1974, excepto no Ciclo Preparatório do Ensino Secundário.

A 2 de Outubro de 1926, a primeira reforma liceal da Ditadura ${ }^{10}$ retira a disciplina de Geografia das $4 .^{\mathrm{a}}$ e $5 .^{\mathrm{a}}$ classes. Esta esvazia-se cada vez mais das preocupações de cidadania e de interpretação da actualidade que marcaram a segunda metade de XIX ${ }^{11}$. As autoridades pretendem livros de Geografia pouco volumosos e de ilustração parcimoniosa, alertando-se para os custos associados à mesma, e dá-se continuidade à selecção dos mesmos entre os aprovados previamente pelo governo, de cinco em cinco anos.

Em 1929, nas instruções sobre os programas dos cursos complementares (6. ${ }^{\circ}$ e $7 .^{\circ}$ ano, onde é disciplina opcional), as autoridades insistem em que os livros não são para decorar, mas apenas fontes de informação ${ }^{12}$; nos trabalhos práticos de Geografia, são indispensáveis os livros de consulta e estatísticas para apoio ao estudo e solução de problemas. No ano seguinte, uma nova reforma acentua a desvalorização do ensino de Geografia ${ }^{13}$ : nos dois primeiros anos, ela é associada a ciências naturais, na disciplina de Ciências da Natureza. Nas 3. ${ }^{\mathrm{a}}$, 4. ${ }^{\mathrm{a}}$ e $5 .^{\mathrm{a}}$ classes, integra a disciplina de Geografia e História, em que o ensino de Geografia dispóe só de uma hora semanal. A Geografia subsiste autonomamente apenas nas duas últimas classes liceais. Em 1931, o Estatuto do Ensino Secundário ${ }^{14}$ defende o livro único, intérprete seguro dos programas, mas reconhece a dificuldade em o retomar. O programa de Geografia da $7 .^{\mathrm{a}}$ classe, então aprovado, refere que o professor se deve cingir quanto possível, ao compêndio e que este se deve documentar profusamente, sempre que seja possível com fotografias, cartas e gráficos de fenómenos observáveis em Portugal e nas colónias portuguesas ${ }^{15}$; institui-se um guia de trabalhos práticos para esta disciplina. Entretanto, o Estado Novo vai ditando para os livros de Português frases de vincada inspiração salazarista e dedica, ainda, uma atenção prioritária aos livros de História.

\footnotetext{
10 Decreto n. ${ }^{\circ} 12425$, de 2 de Outubro.

11 Decreto n. ${ }^{\circ}$ 12594, de 2 de Novembro de 1926.

12 Decreto n. ${ }^{\circ} 16362$, de 14 de Janeiro.

13 Decreto n. ${ }^{\circ} 18885$, de 27 de Setembro.

14 Decreto n. ${ }^{\circ} 19244$, de 16 de Janeiro.

15 Decreto n. ${ }^{\circ} 20369$, de 8 de Outubro.
} 
As dificuldades das autoridades em aprovarem compêndios são enormes, como sucede em Geografia, e, nesta situação, concede-se liberdade de escolha aos professores. Entretanto, a reforma curricular de $1934^{16}$ determina a não adopção de qualquer livro de Ciências da Natureza, devendo o professor socorrer-se de mapas, colecções de animais, plantas, minerais, etc. Contraditoriamente, na reforma curricular do ano seguinte ${ }^{17}$, insiste-se em que, no Curso Complementar, o professor de Geografia não extravase os conteúdos do manual. Também em $1935^{18}$, as autoridades reconhecem que se vive uma situação confusa, sem livros aprovados e flexibilizam a sua selecção.

Em $1936^{19}$, a disciplina de Geografia atinge a sua maior desvalorização o ensino curricular: nos três primeiros anos, os seus conteúdos são inseridos na disciplina de Ciências Geográfico-Naturais; alguns apenas no $7 .^{\circ}$ ano, mas já no $2 .^{\circ}$ se-mestre, reaparece uma escassa disciplina de Ciências Geográficas, com conteúdos de Cosmografia, Geo-Fisica e o da Geo-História. Considera-se, agora, imprudente não adoptar um compêndio para os três primeiros anos, de texto reduzido e muitas fotografias, cartas, quadros estatísticos e gráficos. No $7 .^{\circ}$ ano, para além do compêndio, existirá, ainda, um caderno de observações.

Na sequência da sucessiva e contraditória legislação, proliferam autores cujos manuais tinham sido proibidos pela República. Dos novos, apenas Alves de Moura continuará com uma assinalável produção e António Matoso prosseguirá a sua carreira de autor, mas depois apenas de História. Este advogado é o último representante de autores atentos aos aspectos políticos da organização do território. Os professores liceais Albano Fernandes e João Martins Godinho, com formação na área de Geografia e de Ciências, respectivamente, ilustram bem os pares de autores surgidos na sequência da instituição da disciplina de Ciências Geográfico-Naturais.

\section{ESTATUTO LICEAL DE 1947: UMA GEOGRAFIA RENOVADA E DE LIVRO ÚNICO}

Com o Estatuto Liceal de $1947^{20}$, o ensino de Geografia é revalorizado: nos dois primeiros anos liceais, funciona a disciplina de Ciências Geográfico-Naturais; a Geografia regressa do $3 .^{\circ}$ ao $7 .^{\circ}$ ano liceal. Quando pelo mundo progridem as ideias anti-colonialistas, esta disciplina constitui um instrumento privilegiado de identificação dos jovens com o seu país e, em particular, com as colónias.

16 Decreto-lei n. ${ }^{\circ} 23982$, de 8 de Junho.

17 Decreto n. ${ }^{\circ} 25414$, de 28 de Maio.

18 Decreto-lei n. ${ }^{\circ} 25447$, de 1 de Junho.

19 Decreto-lei n. ${ }^{\circ} 27084$, de 14 de Outubro.

20 Decreto-lei n. ${ }^{\circ}$ 36507, de 17 de Setembro. 
Impõe-se o livro único para todas as disciplinas, um por ciclo. Em Geografia, os atlas são de escolha livre e proíbem-se outros livros auxiliares. Em 1948 e 1949, estas determinações são transpostas para o Ensino Profissional Industrial e Comercial, onde a disciplina de Geografia tem uma menor relevância. Em $1948^{21}$, publicam-se os novos programas e abre-se concurso para os compêndios únicos, a adoptar a partir de 1 de Outubro de 1950.

\section{UM QUASE ÁLBUM PARA CIÊNCIAS GEOGRÁFICO-NATURAIS}

Segundo o programa de 1948 , o compêndio do $1 .^{\circ}$ ciclo não deve ter erros de doutrina (incorrecções) e ser quase um álbum de gravuras. Os concursos abertos em 1948, 1952 e 1954 para o compêndio de Ciências Geográfico-Naturais não levam a qualquer aprovação, embora alguns autores ou grupos de autores tenham publicado livros para a disciplina. Enfim, na sequência do concurso de 16 de Julho de 1955 é adoptado, em 29 de Maio de 1957, Ciências Geográfico-Naturais de JoAQUim Faria CORREIA MONTEIRO - livro que tivera a sua primeira edição em 1950, como outros. O governo hesitou na escolha do livro obrigatório. Correia Monteiro faz um grande esforço de ilustração, mas o seu livro não é quase um simples álbum, como as autoridades solicitam no programa. A aprovação do livro é renovada em 1963 e em 1967.

Joaquim Correia Monteiro é um discreto professor efectivo do Liceu de Passos Manuel, em Lisboa, tendo antes sido assistente de Geografia da Faculdade de Letras da Universidade de Coimbra.

\section{A PREFERÊNCIA POR JOVENS AUTORES NO $2 .^{\circ}$ CICLO}

Para o $2 .^{\circ}$ ciclo, as autoridades insistem no respeito do programa e num texto de complexidade crescente, com elementos de consulta, como estatísticas e gráficos, e abundantes ilustrações e mapas; os autores não devem esquecer os princípios da conexão e da actividade.

Apesar de várias candidaturas ao compêndio de Geografia do $2 .^{\circ}$ ciclo, em 1949, também em 1950 não é aprovado qualquer livro para este grau de ensino, o que se repete em 1952. Contudo, as autoridades já tinham feito saber, informalmente, a dois autores, a sua intenção de aprovar os seus livros: Amílcar Patrício e Júlio Leal de Loureiro. Eram desconhecidos e deveriam continuar a publicar os seus livros, adquirindo notoriedade. Outros concorrentes, em particular Eduardo Alves de Moura, Américo Palma e Evaristo Vieira, os dois primeiros proprietários da Didáctica Editora, já teriam o prestígio que faltava aos mais jovens.

21 Decreto n. ${ }^{\circ}$ 37112, de 22 de Outubro. 
Em Setembro de 1949, ao dirigirem-se às autoridades que apreciarão os seus compêndios para o $2 .^{\circ}$ ciclo, os autores tendem a coincidir no reduzido tempo para a redacção dos seus compêndios e nas preocupações com a ilustração, com Leal de Loureiro e Amílcar Patrício a comprometerem-se, caso o seu livro fosse aprovado, a melhorarem a mesma. Na candidatura de 1954, Martins Godinho e Gonçalves da Cunha sublinham que, sempre que possível, utilizam ilustrações de exemplos portugueses ${ }^{22}$.

O concurso de 18 de Setembro de 1954 leva à adopção, em 12 de Julho de 1955, do Compêndio de Geografia, de Júlio Leal Loureiro e Amílcar Augusto Patrício. Esta aprovação é renovada em 25 de Junho de 1960, mas não em 1965: o sistema de compêndio único esboroa-se através de uma actuação concertada de editores e autores, com a aceitação tácita das autoridades educativas. É preferível correr o risco de sofrer a concorrência de outros autores, mas auferir lucros directos pela edição dos compêndios escolares, de preço livre e que permitem a introdução de imagens a cores. A partir de 1965, Amílcar Patrício e Leal de Loureiro venderam milhares de livros, beneficiando da convicção de muitos de que os seus livros eram obrigatórios. É o livro único informal. A sua obra escrita é escrita em linguagem clara e sóbria, mesmo quando é feita a abordagem de Portugal, ilustrada por fotografias, desenhos e mapas, ao encontro do que se solicita nos programas (fig. 1).

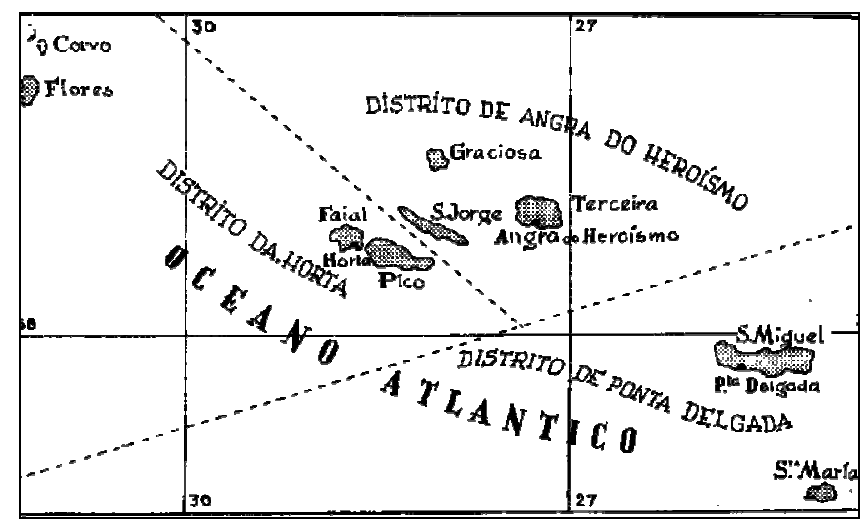

Fig. 1 - Mapa dos Açores (Loureiro e Patrício, 1955, p. 334)

Fig. 1 - Map of Azores (LOUREIRO and PATRÍcIO, 1955, p. 334)

Em qualquer caso, em 1967, Evaristo Vieira, Alves de Moura e Américo Palma reiniciam a publicação do seu Compêndio de Geografia, para cada um dos níveis do $2 .^{\circ}$ ciclo liceal. O Estatuto Liceal está cada vez mais distante e tanto

22 Informação manuscrita recolhida no Arquivo Histórico do Ministério da Educação. 
Estevão Pinto (outro dos autores que tentara a aprovação oficial) como Altino Lopes publicam proibidos livros de exercícios de Geografia.

\title{
VII. NO 3. ${ }^{\circ}$ CICLO, UM LIVRO ÚNICO DIFERENTE
}

\author{
A publicação deste tão esperado livro veio suprir uma falta que \\ já há muito se fazia sentir, tornando mais fácil a tarefa do \\ ensino da geografia do $3 .^{\circ}$ ciclo dos liceus. Os AA., já bastante \\ conhecidos por obras anteriormente publicadas, viram coro- \\ ados de êxito todos os seus esforços com a aprovação do \\ Compêndio de Geografia como livro único.
}

Fernanda VelHo, 1957

O programa de 1948 determina que, para o $7 .^{\circ}$ ano liceal Não haverá compêndio propriamente dito, mas uma indicação de bibliografia, estatísticas, mapas, sendo o professor um orientador, companheiro de trabalho, um crítico. Como motivo de preferência para aprovação, surge a simples indicação de bibliografia, de mapas, estatísticas e, ainda, as gravuras e monografias sobre produções coloniais. Pretende-se que os alunos adquiram a noção de que $o$ nosso Império representa um valor em potencial, que é preciso estudar e conhecer para dirigir a sua evolução, pelo que o aluno deve aprender a tomar iniciativas, a resolver dificuldades, a encarar os problemas... não através do prisma que o mestre lhe fornece ${ }^{23}$. O Estado Novo torna a surpreender pelo arrojo pedagógico do seu discurso.

Só em 29 de Maio 1957, após vários concursos sem qualquer aprovação, é adoptado o compêndio de Geografia de Eduardo Marinho Alves de Moura e Evaristo Guedes Vieira, com $1 .^{a}$ edição nesse mesmo ano. Numa inusitada Advertência, quando iniciam a parte relativa ao $7 .^{\circ}$ ano, transcrevem as indicações do programa e declaram que as vão cumprir. Na realidade, no que concerne ao $7 .^{\circ}$ ano, o compêndio consta de uma abundante bibliografia, de monografias e de uma antologia organizada por autores.

ALVES DE Moura, que protestara contra a apreciação desfavorável ao seu livro candidato ao $2 .^{\circ}$ ciclo, não permite às autoridades que reprovem mais este livro de que é co-autor. A renovação da aprovação deste livro ocorre em 1962 e 1967, continuando a ser publicado, já sem a classificação de compêndio oficial, a partir de 1972. Para este ciclo, merece referência, também, como livro auxiliar, Geografia: Problemas e Resoluções, de Alves de Moura e Américo Palma, com 12. ${ }^{\text {a }}$ edição, em 1974 - mais um livro proibido pelo Estatuto de 1947.

23 Decreto n. ${ }^{\circ}$ 37112, de 22 de Outubro de 1948. 


\section{OS RESPEITÁVEIS AUTORES E METODÓLOGOS}

Os autores dos livros únicos dos $2 .^{\circ}$ e $3 .^{\circ}$ ciclos liceais constituem uma verdadeira elite do ensino liceal do Estado Novo-com excepção de Alves de Moura, a sua condição de autores seleccionados também os projectou no mundo liceal de então.

Amílcar Augusto Patrício (Figueira de Castelo Rodrigo, 1913-1993), filho de um professor do ensino primário, licencia-se em Ciências Geográficas na Universidade de Coimbra, em 1939 e, no ano seguinte, conclui o curso de Ciências Pedagógicas. Bolseiro do Instituto de Alta Cultura, colabora com Amorim Girão no Atlas de Portugal (1941) e na Geografia de Portugal (1942). Entretanto, efectua o estágio no Liceu Normal de Coimbra, interessa-se pela docência liceal e recusa o convite de Amorim Girão para seu assistente, recusa que repete, mais tarde, a Orlando Ribeiro, com quem desenvolve alguma investigação. Em 1949, convida Júlio Leal de Loureiro para concluir com ele o compêndio que iniciara para o $2 .^{\circ}$ ciclo, de acordo com os programas do ano anterior. Professor consagrado, não consegue evitar ser nomeado Reitor do Liceu de Leiria. Em 1965/66, desloca-se para Lisboa e recusa novas nomeações para reitor. No entanto, em 1969/70 aceita ser professor metodólogo, tarefa mais directamente relacionada com a docência. Após o 25 de Abril, ainda publica alguns livros.

Júlio Leal de Loureiro (Viseu, 1909-1990) é filho de dois professores do ensino primário. Ingressa no curso de Ciências Histórico-Geográficas, na Universidade de Lisboa, mas faz a maioria do seu curso na Universidade de Coimbra, onde é aluno de Amorim Girão. Muito jovem, é professor metodólogo no Liceu Pedro Nunes, após o que, já no Liceu de Aveiro, inicia a redacção de compêndios, com Amílcar Patrício. No Porto, assumirá, por longos anos, as funções de professor metodólogo. Para além dos compêndios de Geografia, é autor ou co-autor de outras obras escolares.

Eduardo Marinha Alves de Moura (Celorico de Basto, 1895-1991) é, também, filho de um professor do ensino primário. Na Universidade de Lisboa, é discípulo de Silva Teles. Adepto do ensino experimental, notabiliza-se pelos trabalhos práticos de Geografia que desenvolve no Liceu de Faro, onde é reitor. Em 1930, é o primeiro professor metodólogo do Liceu Normal de Lisboa (função que abandona no começo dos anos 40) e inicia uma colaboração regular com a prestigiada revista liceal Labor. Empenha-se particularmente na nova disciplina de Ciências da Natureza. Protesta contra os maus tratos de que a Geografia é vítima nos anos 30, preocupando-se igualmente com as questões educativas, mais em geral. Este defensor do papel dos compêndios e da sobriedade dos mesmos, é um dos fundadores, em 1944, da Livraria Didáctica, que depois abandonará; em 1970, funda a Editorial O Livro e, dois anos depois, a Plátano Editora. Com Evaristo Vieira, continuará a publicar livros para os últimos anos liceais depois do 1974. Fascinado pelo mundo, redigirá ainda livros sobre a astronomia, a conquista do espaço, o esperanto ou a Filosofia. 
Evaristo Guedes Vieira (Elvas, 1909-1979) forma-se em Ciências HistóricoGeográficas na Universidade de Lisboa. Filho de um militar que participa numa revolta contra a Ditadura, é olhado com desconfiança pelo regime, só encontra emprego em colégios particulares, até conseguir ingressar nos liceus, já nos anos 40. Em 1948/49, torna-se professor metodólogo do liceu normal de Coimbra, transferindo-se depois para Lisboa, onde retomará, nos anos 60, as funções de metodólogo. Nos começos dos anos 60, representa Portugal em três Conferências para a Revisão dos Manuais Escolares de Geografia do Conselho da Europa. Colabora activamente na revista Palestra. Não se lhe é esquecida a fama de opositor ao regime e, com a Revolução de 1974, é chamado ao Ministério da Educação para coordenar a reformulação dos programas de Geografia, que então se efectua.

$\mathrm{Na}$ realidade, a selecção do livro único acabou por fazer evidenciar um pequeno grupo de professores e autores de assinalável mérito. Na sua obra, foram influenciados por Amorim Girão, de que dois deles foram alunos, como se referiu, mas foram igualmente marcados pela obra de Orlando Ribeiro, de que alguns foram colegas na universidade (Leal de Loureiro e Evaristo Vieira). São derrotados mais pelos limites da longevidade humana que por uma revolução que derrubou um regime e um império que, discretamente, serviram.

\section{O QUASE INEXISTENTE COMPÊNDIO ÚNICO NO ENSINO TÉCNICO PROFISSIONAL}

No ensino técnico, as indicações sobre o compêndio de Geografia criticam igualmente a concepção como repositório de informações e valorizam também o papel da ilustração. Em $1947^{24}$, exige-se que o manual de Ciências Geográfico-Naturais seja apenas um guia didáctico das actividades a desenvolver, admitindo-se uma sóbria exposição, apenas a título excepcional. Nos programas de Geografia Geral e Económica ${ }^{25}$, são apontados como parâmetros prioritários a apresentação gráfica e, só depois, a exactidão da doutrina, devendo o texto ser reduzido ao necessário. O livro deve ser pouco extenso, bem ilustrado e com muitos quadros de dados.

Apenas conhecemos um compêndio de Geografia adoptado como livro único no ensino técnico profissional, em 1954, de Oliveira Boléo e Alves de Moura, para o Curso Geral do Comércio ${ }^{26}$. Já com a co-autoria de Américo Palma ele é sucessivamente reeditado, designadamente nos anos 60, pela Didáctica Editora, sem o timbre de livro único. Américo Palma e Alves de Moura, a que se associam, nos anos 50 e 60, Oliveira Boléo, António Matoso,

24 Decreto n. ${ }^{\circ} 36356$, de 18 de Junho.

25 Portaria n. ${ }^{\circ} 13800$, de 12 de Janeiro de 1952.

26 Diário do Governo, II Série, n. ${ }^{\circ}$ 136, de 9 de Junho, p. 3527. 
João Augusto Marques de Almeida, Hildeberto de Medeiros e, episódica e ficticiamente, Ângelo Martins Raposo, quase monopolizam, em diversas reedições daquela editora, os compêndios no ensino técnico. Talvez sem a pressão do livro único, estes livros não seguem, de forma tão rígida, as indicações dos programas. Mas também neste ensino estamos longe do compêndio que assume, sobretudo, a forma de guia didáctico de actividades - as ilustrações serão muitas, mas domina a função expositiva tradicional.

A prática ausência de livros únicos de Geografia no ensino secundário técnico e profissional, decorrerá da maior diversidade de cursos, do menor número de alunos mas, também, de a preocupação dominante do poder político se dirigir para o ensino liceal, mais vocacionado para a formação das classes dirigentes.

\section{NO PREPARATÓRIO, A LIBERDADE DE ESCOLHER COMPÊNDIOS APOLOGISTAS DO COLONIALISMO}

A partir da segunda metade dos anos 60 , é publicada sucessiva legislação com um discurso pedagógico inovador, também em relação aos compêndios. Há uma contestação crescente ao livro único e Alves de Moura (1967: 189) interroga-se: Até quando, livro-único, abusarás da nossa paciência?

Em 1967, institui-se o ciclo preparatório do ensino secundário e, em 10 de Março do mesmo ano ${ }^{27}$, reconhece-se a progressiva necessidade de promover a gradual adaptação dos planos de estudo, programas, textos, métodos e condições de ensino aos progressos científicos e pedagógicos. No ano seguinte, procede-se à aprovação dos primeiros programas, com o país a viver a guerra colonial. A disciplina de Ciências Geográfico-Naturais é substituída pela mais útil História e Geografia de Portugal, onde se afirma que A consciência de cada pequeno português deverá despertar e fortalecer-se ao conhecer exaltadamente a história da sua pátria e ao ver esclarecidamente a largueza e a promessa do vastíssimo território que ela abrange ${ }^{28}$. Em 1968, o Estatuto do Ciclo Preparatório do Ensino Secundário ${ }^{29}$ repõe a liberdade de escolha dos compêndios pelos conselhos escolares, de entre os autorizados, por cinco anos, pelo Ministério da Educação Nacional. Contudo, as autoridades são claras: só se aprovam livros em conformidade com a doutrina e moral cristãs tradicionais do País e com os superiores interesses e valores da Nação portuguesa. Os avisos de abertura de concurso reforçam as exigências de carácter ideológico. Em 1970 30, autorizam-se quatro compêndios de História e Geografia de Portugal, todos eles

27 Decreto-lei n. ${ }^{\circ} 47587$

28 Portaria n. ${ }^{\circ} 23601$, de 9 de Setembro.

29 Decreto n. ${ }^{\circ} 48572$, de 9 de Setembro de 1968.

30 Diário do Governo, II Série, n. ${ }^{\circ}$ 177, de 1 de Agosto, p. 5683. 
de dois volumes, para os primeiro e segundo anos. Num total de nove autores, apenas dois são professores de Geografia: Maria Helena Cavaco e o conhecido Amílcar Patrício.

\section{A EVOLUÇÃO NÃO ASSUMIDA NA LEGISLAÇÃO}

Em 1971, uma circular da Direcção-Geral do Ensino Liceal ${ }^{31}$ : i) apela à afixação atempada da lista dos livros adoptados no preparatório e nos restantes níveis, a fim de permitir a sua aquisição pelos alunos; ii) obriga os reitores a informarem os editores dos livros escolhidos e do número previsível de alunos; e iii) tenta estabilizar as escolhas dos mesmos livros, ao obrigar à manutenção das adopções por, pelo menos, dois anos-são crescentes as dificuldades em assegurar um fornecimento em tempo útil dos compêndios. Os preços destes aumentam assinalavelmente e, em 1973, são sujeitos ao regime de homologação prévia ${ }^{32}$. Contudo, continua formalmente em vigor o estatuto liceal de 1947. O Diploma Orgânico da Direcção-Geral do Ensino Secundário, também de $1973^{33}$, substitui a caduca Comissão Administrativa do Livro Único pela Comissão Administrativa do Livro Escolar. Na Assembleia Nacional, um deputado denuncia o ensino transmissivo e acusa o livro único de refinar esta antididáctica (Ministério da Educação Nacional, 1973, p. 462). Anuncia-se, para breve, um novo ciclo.

De forma indirecta, Carlos Alberto Medeiros irá também participar no novo ciclo de compêndios de Geografia, que se inicia com a revolução de 1974. Os autores escolares vão recolher ensinamentos e efectivar numerosas citações da obra de síntese sobre a Geografia de Portugal do então já conhecido professor universitário.

\section{BIBLIOGRAFIA}

GIRão, A. (1934)-Compêndios de geografia para o ensino primário (notas e críticas). Coimbra Editora, Coimbra.

Loureiro, J. L.; Patrício, A. (1955) - Compêndio de Geografia para o $2 .^{\circ}$ Ciclo dos Liceus, VolII-4. ${ }^{\circ}$ e 5. ${ }^{\circ}$ anos. Porto Editora, Porto.

Marques, A. H. O. (1984)-História de Portugal-Das Revoluções liberais aos nossos dias, Vol. III. Palas Editores, Lisboa, 3. ${ }^{\text {a }}$ Edição.

31 Ministério da Educação - Direç̧ão-Geral do Ensino Liceal, Seç̧ão Pedagógica L. ${ }^{\circ} 1 / 7 \mathrm{~L}$ Pr. ${ }^{\circ}$. 1/39, Circular n. ${ }^{\circ} 2524$.

32 Portaria n. ${ }^{\circ} 692 / 73$, de 10 de Outubro.

33 Decreto-lei n. ${ }^{\circ}$ 44/73, de 12 de Fevereiro. 
Ministério da EducaÇão Nacional (1973) - A Reforma do Ensino Secundário. Divisão de Documentação da Secretaria-geral do Ministério da Educação Nacional, Lisboa.

MourA, A. (1967) - Quousque Tandem. Labor, XXXI (3. a Série), 253: 189-191.

Velho, F. (1957) - Evaristo Vieira e Alves de Moura, Compêndio de Geografia para o 3. ${ }^{\circ}$ ciclo liceal, Sá da Costa, Lisboa, 1957. Boletim do Centro de Estudos Geográficos, II (14, 15): 127 p. 